\title{
Cardiovascular Pharmacology: Open Access
}

\section{$\beta_{2}$-Adrenoceptors Antiarrhythmic Effects in Wild Type Mice Fed a Cholesterol-Enriched Diet}

\begin{abstract}
Simone Correia Ternes ${ }^{1}$, Leandro Eziquiel de Souza ${ }^{2}$, Paula Lazara Cruz ${ }^{2}$, Cristiano Teixeira Mostarda ${ }^{3}$, Maria Cláudia Costa Irigoyen ${ }^{2}$, Vitor Rossi de Almeida ${ }^{1}$, André Luiz de Moura ${ }^{1}$, Luciana Le Sueur Maluf', Daniela Ortolani', Daniel Araki Ribeiro', Isabel Cristina Céspedes ${ }^{1}$ and Regina Célia Spadari ${ }^{1 *}$
\end{abstract}

${ }^{1}$ Departamento de Biociências, Campus Baixada Santista, Universidade Federal de São Paulo, Santos, Sao Paulo, Brazil ${ }^{2}$ Departamento de Hipertensão, Instituto do Coração, Hospital das Clínicas, Universidade de São Paulo, São Paulo, Brazil

${ }^{3}$ Programa de Pós Graduação em Saúde do Adulto e da Criança, Universidade Federal do Maranhão, Maranhão, Brazil

\begin{abstract}
The systematic intake of an unbalanced diet is an important risk factor for cardiovascular diseases, the leading cause of death in the entire world. Most of the studies address this issue using genetically manipulated mice. This study aims to investigate the effect of the intake of a cholesterol-enriched diet on cardiac and hemodynamic parameters in conscious wild type mice. Twenty male, three-month-old C57BL/6 mice were distributed in two groups: $(\mathrm{CTL})$ control, with mice receiving standard commercial chow and $(\mathrm{CHO})$ cholesterol group, with mice receiving a cholesterol-enriched diet during 15 days. Catheters were implanted in the carotid artery and jugular vein for blood pressure and heart rate recording and drugs administration. Electrodes were implanted for electrocardiogram recording and spectral analysis of heart rate variability. Glucose, cholesterol, and triglycerides were determined in blood samples and histopathological analysis of the aorta was performed. Serum cholesterol and glucose, mean arterial pressure and heart rate were higher in $\mathrm{CHO}$ than $\mathrm{CTL}$ mice. $\mathrm{CHO}$ mice also exhibited predominance of sympathetic over parasympathetic tonus to the heart, and higher responsiveness to the chronotropic effect of isoproterenol. Arrhythmic episodes, present only in the $\mathrm{CHO}$ mice, were cancelled by metoprolol and exacerbated by ICl118,551. It is concluded that the intake of high cholesterol diet causes hypertension and heart rhythm irregularities. Because those effects are exacerbated by the blockade of $\beta_{2}$-adrenergic receptor and attenuated by the blockade of $\beta_{1}$-adrenergic receptor, data highlights a possible antiarrhythmic protective role played by $\beta_{2}$-AR subtype.
\end{abstract}

Keywords: Cholesterol diet; Dyslipidemia; $\beta$-adrenergic receptors; $\beta$-adrenergic antagonists; Cardiac arrhythmias

\section{Introduction}

The high incidence of cardiovascular events, in which arrhythmias and sudden cardiac death are prevalent, is associated with Hypercholesterolemia (HC), atherosclerosis, systemic hypertension, and obesity [1,2]. Evidence suggests that hypercholesterolemia contributes to the progression of hypertension through the activation of the renin-angiotensin system, reducing the availability of Nitric oxide (NO) thus causing endothelial dysfunction [3-5]. $\beta$-adrenoceptors ( $\beta$-ARs) play important roles in the regulation of blood pressure and vascular tone, as well as cardiac function. When activated by catecholamines, $\beta_{1}-\left(\beta_{1}-\mathrm{AR}\right)$ and $\beta_{2}$-adrenoceptor $\left(\beta_{2}-\mathrm{AR}\right)$ subtypes activate Gs protein/adenylyl cyclase pathway which results in positive effects on the electrical properties and mechanical performance of the heart by increasing beating rate and strength, the action potential conduction, cardiomyocytes contraction and relaxation rates [68]. These receptors also control cardiomyocytes metabolism and life cycle $[9,10]$. It is now accepted that $\beta_{1}$-AR overstimulation may have important clinical implications in certain pathogenic conditions such as congestive heart failure [11-13]. Under certain circumstances, $\beta_{2}-\mathrm{AR}$ may alternatively couple to $\mathrm{Gi}$ and thus activate PI3K/AKT pathway which will protect the heart from apoptosis [14]. Right atria isolated from LDL receptor knockout mice (LDLr-/-) fed cholesterol-enriched diet have higher basal beating rate and sensitivity to the chronotropic effect of isoproterenol as compared to LDLr-/-mice fed regular chow. The in vitro blockade of $\beta_{2}$-ARs with ICI118, 551 or the inhibition of Gi protein by Pertussis toxin resulted in arrhythmia [15].

However, the effect of the intake of a cholesterol-enriched diet has not been investigated in vivo in non-genetically manipulated mice. This work objective to evaluate the effect of such diet on hemodynamic and cardiac parameters of non-genetically manipulated mice, especially the role played by the $\beta_{2}$-AR subtype in those processes.

\section{Material and Method}

\section{Animals}

The experimental protocols were approved by the Institutional Committee for Ethics in Animal Experimentation under protocol number 2084/11, and it is in agreement with the guidelines of the Brazilian College for Animal Experimentation (COBEA).

Twenty male three-month-old C57BL/6 mice weighing $24 \pm 3 \mathrm{~g}$ were obtained from the "Instituto do Coração" colony (InCor, São Paulo, SP, and Brazil). The mice were housed in standard cages (3-4 mice/cage) in a temperature-controlled room $\left(22^{\circ} \mathrm{C} \pm 1\right)$, on a $12 / 12$ $\mathrm{h}$ light/dark cycle with the lights on at 6:30 a.m. After one week acclimation period, the mice were implanted with electrodes and blood vessel catheters as described below. Then they were housed individually. Food and tap water were available ad libitum.

*Corresponding author: Regina Celia Spadari, MD, PhD, Biology of Stress Laboratory, Biosciences Department, Rua Silva Jardim, 136 - Vila Matias, Santos - SP, 11015-020, Brazil, Tel: +55-13-3878 3827; E-mail: regina.spadari@unifesp.b

Received July 29, 2016; Accepted September 21, 2016; Published September 26, 2016

Citation: Ternes SC, Souza LED, Cruz PL, Mostarda CT, Irigoyen MCC, et al. (2016) $\beta_{2}$-Adrenoceptors Antiarrhythmic Effects in Wild Type Mice Fed a Cholesterol-Enriched Diet. Cardiovasc Pharm Open Access 5: 196. doi: 10.4172/2329-6607.1000196

Copyright: (C) 2016 Ternes SC, et al. This is an open-access article distributed under the terms of the Creative Commons Attribution License, which permits unrestricted use, distribution, and reproduction in any medium, provided the original author and source are credited. 
Mice were randomly allocated to one of the following groups according to the diet: (CTL, $\mathrm{n}=10)$ control group with mice receiving standard commercial chow (Nuvital CR1, Paraná, Brasil) and (CHO, $\mathrm{n}=10$ ) cholesterol group with mice receiving a high fat diet containing: $20 \%$ fat, $1.25 \%$ cholesterol and $0.5 \%$ cholic acid (Diets, Bethlem, PA, USA). All mice were weighted at the beginning and at the end of the experimental period and food consumption was measured once a week.

\section{Surgical procedures}

Mice were anesthetized with ketamine hydrochloride $(80 \mathrm{mg} / \mathrm{kg}$, i.p., König Lab S.A., São Paulo, SP, Brazil) and xylazine (16 mg/kg, i.p., Virbac do Brasil, São Paulo, SP, Brazil). In order to record the heart beating, an electrode weighing approximately $300 \mathrm{mg}$ and contained two positive poles on the sides and a central negative pole was installed in the mice cranial region. The positive poles of the electrode were fixed along the intercostal muscles of the animal and the negative pole fixed in the posterior cervical muscle. The electrode connector was fixed in the cranial region and sutured in the skin. After electrode installation, still under anesthesia, two catheters (PE-10) filled with saline solution were surgically implanted in the left carotid artery and left jugular vein, for arterial pressure recording and drugs administration, respectively. The catheters were sutured in place, and tunneled to the back of the animal.

\section{Blood pressure and heart rate recording}

One day after the surgery, blood pressure and heart rate were recorded for about $1 \mathrm{~h}$ and $40 \mathrm{~min}$ with the animal conscious and freely moving into the cage. The arterial catheter was attached to a PE-50 tubing connected to an electromagnetic transducer (P23Db, Gold-Statham, Oxnard, CA, USA), which was connected to a general purpose amplifier (Stemtech Inc., Wood Dale, IL, USA) that converted to digital the blood pressure analog signal. Electrocardiogram was simultaneously recorded by connecting the electrode to a bioelectric amplifier (Hewlett Packard Model 8811A, Waltham, MA, USA). Data were recorded in real time on a microcomputer equipped with Windaq System (Akron, OH, USA) using Windaq software and adjusted for a sample frequency of $4.000 \mathrm{Hertz}$. The heart rate values were compared with data derived from the arterial pressure wave.

\section{Pharmacological assay}

With the mice awake, freely moving in its home cage, the following experimental protocol was performed: (1) ECG and BP were recorded for about 30 min to obtain basal values; (2) Subsequently, mice received an i.v. injection of $3 \mu \mathrm{g} / \mathrm{kg}$ isoproterenol hydrochloride; (3) After returning of blood pressure to baseline, $2.5 \mathrm{mg} / \mathrm{kg}$ metoprolol was administered. Ten minutes after, mice received a second i.v. injection of $3 \mu \mathrm{g} / \mathrm{kg}$ isoproterenol hydrochloride; (4) After returning to baseline, $3 \mathrm{mg} / \mathrm{kg}$ propranolol was administered, followed ten minutes later by an i.v. injection of $3 \mu \mathrm{g} / \mathrm{kg}$ isoproterenol hydrochloride. During the protocol, the blood pressure and electrocardiogram were recorded. Drugs were infused through the arterial catheter as a bolus in a volume of $1 \mu \mathrm{l} / \mathrm{g}$ of body weight.

Another group of mice received a similar treatment, replacing the $\beta_{1}$-selective antagonist metoprolol by the $\beta_{2}$-selective antagonist ICI118, 551 ( $1 \mathrm{mg} / \mathrm{kg}$ of body weight).

After the above described procedures, mice were sacrificed by decapitation and their hearts removed and weighed. Left ventricle, including the interventricular septum was weighed. Cardiac index (heart mass/ body mass) and the left ventricle relative mass (left ventricular mass/body mass) were calculated.
4.5 Spectral analysis of heart rate variability in the frequency domain (autoregressive modeling)

Each heart beating was identified using the algorithm implemented in Windaq/DATAC that automatically detected R-R intervals of the ECG wave. Then, the temporal series of the heart pulse intervals (tachogram) and systolic blood pressure intervals (systogram) were generated. The interpolation of the tachogram and systogram series was used to remove distortions. Data spectral analysis (FFt) was performed using Matlab 7.0 [16].

The power spectrum was integrated into three frequency bands: high frequency (HF), between 1.0 and $5.0 \mathrm{~Hz}$; low frequency (LF), between 0.10 and $1.0 \mathrm{~Hz}$, and very low frequency (VLF), lower than $0.10 \mathrm{~Hz}$.

\section{Histopathological analysis}

The full length of the aortic arch and thoracic aorta from both groups (CTL; $\mathrm{n}=4$, CHO; $\mathrm{n}=5$ ) were collected for histopathological analysis. The samples were fixed by immersion in $10 \%$ buffered formalin, routinely processed and embedded in paraplast (Histosec, Merck, Kenilworth, NJ, USA). Semi-serially sections of $5 \mu \mathrm{m}$ thickness, spaced $30 \mu \mathrm{m}$ from each other were collected. The sections were stained with hematoxylin and eosin (Merck, Kenilworth, NJ, USA), and analyzed at optical microscope (Axio Observer D1, Zeiss, Thornwood, NY, USA) regarding the presence or absence of inflammation. When present, the type of inflammatory cells and intensity of inflammation were evaluated in all mice using the following grades: Normal (0), minimal (1), slight (2), moderate (3), and severe (4). The same investigator, who was blinded for treatment codes, performed the scoring of the histological sections.

\section{Serum Glucose, triglycerides, HDL, LDL and total cholesterol determination}

Blood was collected from the trunk upon decapitation, centrifuged at $3000 \mathrm{rpm}$ for $20 \mathrm{~min}$. Serum was stored at $-20^{\circ} \mathrm{C}$ until glucose, triglycerides, $\mathrm{HDL}, \mathrm{LDL}$ and total cholesterol concentrations were determined using commercial kits (Diagnostic Labtest SA, Belo Horizonte, Minas Gerais, Brazil).

\section{Statistical analysis}

Data are presented as means \pm SEM and the groups were compared by the Student's $t$ test or One-way Analysis of Variance (ANOVA) followed by the Bonferroni test. Differences were considered statistically significant at $\mathrm{p} \leq 0.05$.

\section{Results}

Table 1 shows the body mass, the cardiac and left ventricle mass and the cardiac index at the end of the experiment, as well as the daily food intake during the experimental period. There were no significant differences between groups in any of these parameters. However, the weekly food intake was lower in the $\mathrm{CHO}(22.2 \mathrm{~g} /$ week/mice $)$ than control group (15 g/week/mice).

The serum concentrations of glucose, triglycerides, HDL, LDL and total cholesterol are shown in Table 2. Glucose, total cholesterol and LDL cholesterol levels were higher in CHO mice than in CTL mice $(\mathrm{p}<0.05)$, whereas triglycerides and HDL cholesterol levels showed no difference between the groups.

No alteration compatible with atherosclerotic plaque formation was seen in the samples of aortic arch or any segment of thoracic aorta 


\begin{tabular}{|c|c|c|}
\hline & CTL (n=8) & CHO (n=8) \\
\hline Body mass (g) & $23 \pm 0.5$ & $22 \pm 0.7$ \\
\hline Daily food intake g/animal/day & $3 \pm 2$ & $2 \pm 5$ \\
\hline Cardiac mass (mg) & $113 \pm 2.5$ & $113 \pm 2.1$ \\
\hline Left ventricle mass (mg) & $77 \pm 1.3$ & $77 \pm 1.5$ \\
\hline Cardiac index (\%) & 0.45 & 0.47 \\
\hline
\end{tabular}

Table 1: Body mass, food intake, cardiac mass, left ventricle mass, and cardiac index (cardiac mass/body mass) of mice fed standard chow (CTL) and mice treated with cholesterol-enriched diet ( $\mathrm{CHO})$. Data are presented as means $\pm \mathrm{SEM}$. There was no statistically significant difference between groups; Student $t$ test.

\begin{tabular}{|c|c|c|}
\hline & CTL $(\mathbf{n = 4})$ & CHO $(\mathbf{n = 5})$ \\
\hline Glucose $(\mathrm{mg} / \mathrm{dL})$ & $85 \pm 6$ & $1067^{*}$ \\
\hline Triglycerides $(\mathrm{mg} / \mathrm{dL})$ & $74 \pm 4$ & $77=3$ \\
\hline Total cholesterol $(\mathrm{mg} / \mathrm{dL})$ & $98 \pm 3$ & $264 \mathrm{n}-2^{*}$ \\
\hline HDL cholesterol $(\mathrm{mg} / \mathrm{dL})$ & $41 \pm 7$ & $41=6$ \\
\hline LDL cholesterol $(\mathrm{mg} / \mathrm{dL})$ & $41 \pm 7$ & $2067^{*}$ \\
\hline
\end{tabular}

Table 2: Serum concentrations of glucose, triglycerides, total cholesterol, HDL cholesterol and LDL cholesterol in fasted control (CTL) and $\mathrm{CHO}$ mice. Animals were overnight fasted. Data are means \pm SEM. Statistically different from Control; " $p<0.05$; Student $t$ test.

(Figure 1), except for two of the six mice fed a high cholesterol diet in which punctual lesions have been localized, with inflammatory cells and foam cells in the tunica intima and a discrete accumulation of white blood cells in the tunica media. Both, control and experimental groups scored between normal (0) and minimal (1) with no difference between groups regarding to inflammation intensity (Table 3 ).

The heart rate and the mean arterial blood pressure as well as systolic and diastolic blood pressure were higher in $\mathrm{CHO}$ mice than they were in control mice (Table 4). A significant decrease in the mean arterial blood pressure was seen in response to isoproterenol in both groups (Figure 2). Metoprolol (panel A) or ICI 118,551 (panel B) did not cause any alteration in the blood pressure under basal conditions. Isoproterenol also induced an increase in the heart rate of CTL and $\mathrm{CHO}$ mice (Figure 3). Metoprolol did not alter the response to isoproterenol in either CTL or CHO group (Figure 3, panel A). ICI 118,551 reduced the response to isoproterenol in the $\mathrm{CHO}$ group (Figure 3, panel $\mathrm{B}$ ), suggesting that $\beta_{2}$-adrenoceptor participate in the cardiac response to isoproterenol in mice fed a cholesterol-enriched diet.

The analysis of the autonomic modulation of the heart shows a predominance of vagal over sympathetic activity $(61 \pm 2 \%$ vs. $33 \pm$ $3 \%$, respectively) in mice of the control group. However, in mice fed a high cholesterol diet there was a significant increase in sympathetic activity and a reduction of the vagal tonus, reversing the predominant influence and highlighting sympathetic predominance $(39 \pm 2.5 \%$ vs. $66 \pm 3 \%$ ) (Figure 4). LF/HF ratio confirms that in the heart of mice fed a high cholesterol diet the sympathetic activity is higher $(2.25 \pm 0.33)$ than it is in the heart of control mice $(0.65 \pm 0.08)$.

Mice fed cholesterol-enriched diet presented higher incidence of irregular rhythm than those fed standard chow. Arrhythmia was not seen in control mice under basal condition (Figure 5A); however, 6 of 10 mice in the $\mathrm{CHO}$ group exhibited some type of disorder in the heart rhythm, such as: irregular rhythm, ventricular extrasystole and bigeminy, as illustrated in Figure 6.

After the administration of isoproterenol, 3 of 10 mice in the control group had isolated episodes of ventricular extrasystoles (Figure $5 \mathrm{~B}$ ), and during the course of the same period, 6 of 10 mice in the $\mathrm{CHO}$ group showed several breaks and ventricular extrasystoles. Those cardiac rhythm alterations were not observed when isoproterenol was administered after metoprolol, but pauses, irregular rhythm and ventricular extrasystole were present in 3 of 5 control mice (Figure 5C) and 4 of 5 CHO mice after administration of ICI 118,551.

\section{Discussion}

The results of this work show that mice fed a cholesterol-enriched diet for 15 days present higher serum concentrations of total cholesterol, LDL and glucose, as well as higher mean arterial pressure and heart rate as compared to mice fed with regular chow. The daily food intake was not significantly different between groups but the weekly food intake was lower in the $\mathrm{CHO}$ than control group. Thus, there was no significant difference in the body weight, cardiac and left ventricle mass between groups.

The autonomic modulation of the heart was also altered, so that the sympathetic nervous system activity predominated over the parasympathetic drive, while the control mice showed vagal predominance. The intake of the cholesterol-enriched diet also resulted in increased responsiveness to the chronotropic effect of isoproterenol. The infusion the $\beta_{2}$ adrenergic antagonist ICI118,551 cancelled the supersensitivity to isoproterenol and induced arrhythmia.

High blood levels of cholesterol have long been associated with increased risk for coronary disease and myocardial infarction [17]. Genetically modified mice, such as ApoE-/- and LDLr-/-, eating a cholesterol-enriched diet have the atherogenic process accelerated. That is why those mice have been widely used to determine the pathogenesis and treatment of atherosclerosis [18]. Fat intake promotes significant structural changes in arterial walls, particularly through activation of the renin-angiotensin system, induction of oxidative stress and proinflammatory factors $[4,5]$. Those changes in conductance vessels constitute a risk for cardiovascular diseases [19]. LDLr-/-mice fed the same cholesterol-enriched diet that was used here developed dyslipidemia, atherosclerosis, left ventricular hypertrophy, high mean arterial pressure and reduced cardiac contractility [15]. The contractile deficit may lead to reduced cardiac output if compensatory mechanisms were not triggered, such as increased heart rate. Indeed, the basal beating rate of right atria isolated of LDLr-/-mice was higher than that of control mice [15]. However, the effect of a cholesterolenriched diet on cardiovascular parameters of control mice was not analyzed. Data presented here have shown that no inflammatory cells or atherogenesis were observed in the aorta of the wild type mice eating a cholesterol-enriched diet, despite the high levels of cholesterol in the blood, high blood pressure and heart rate.

Additionally, no morphological alteration was seen in the myocardium. However, the heart rate variability was altered in wild

\begin{tabular}{|c|c|}
\hline Group & Inflammatory Score \\
\hline CTL & $0.25 \pm 0.40$ \\
\hline CHO & $1.0 \pm 1.00$ \\
\hline
\end{tabular}

Table 3: Intensity of inflammatory process (expressed as mean \pm SD) in aorta of mice fed with regular chow (control, CTL) and mice fed a cholesterol-enriched diet during 15 days $(\mathrm{CHO})$. Scores varies from 0 (normal) to 4 (severe). There was no statistically significant difference between groups; $p>0.05$; Student $t$ test.

\begin{tabular}{|c|c|c|}
\hline & CTL $(\mathbf{n}=\mathbf{1 0})$ & CHO $(\mathbf{n}=\mathbf{1 0})$ \\
\hline HR $(\mathrm{bpm})$ & $505 \pm 21$ & $589 \pm 23^{*}$ \\
\hline MAP $(\mathrm{mmHg})$ & $107 \pm 4$ & $118 \pm 1^{*}$ \\
\hline SAP $(\mathrm{mmHg})$ & $126 \pm 5$ & $138 \pm 1^{*}$ \\
\hline DAP $(\mathrm{mmHg})$ & $88 \pm 4$ & $99 \pm 1^{*}$ \\
\hline
\end{tabular}

Table 4: Heart Rate (HR), Mean Arterial Pressure (MAP), Systolic (SAP) and Diastolic Arterial Pressure (DAP) of mice fed standard chow (CTL) and mice treated with cholesterol-enriched diet $(\mathrm{CHO})$. Data are presented as means \pm SEM Statistically different from Control; " $p<0.05$; Student $t$ test. 
Citation: Ternes SC, Souza LED, Cruz PL, Mostarda CT, Irigoyen MCC, et al. (2016) $\beta_{2}$-Adrenoceptors Antiarrhythmic Effects in Wild Type Mice Fed a Cholesterol-Enriched Diet. Cardiovasc Pharm Open Access 5: 196. doi: 10.4172/2329-6607.1000196

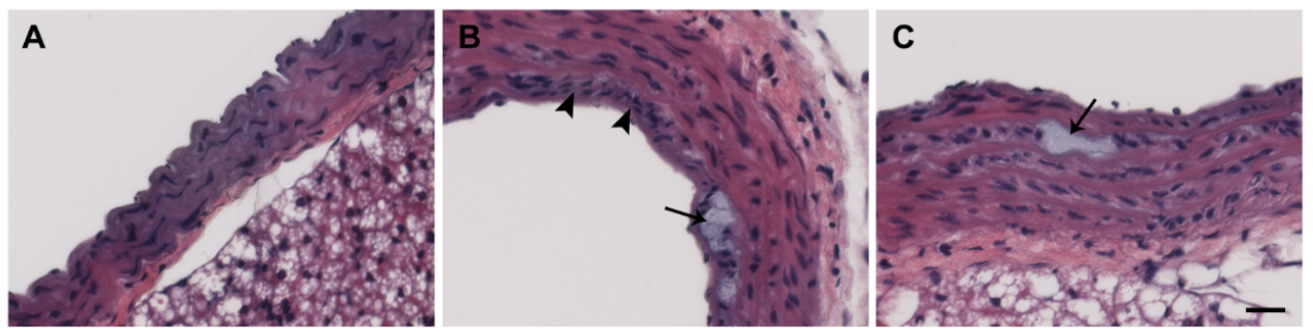

Figure 1: Photomicrography of aortic arch of control mice (panel A) and mice treated with cholesterol-enriched diet (panels B and C). In A note that intima, media and adventitia are preserved. In B and $\mathrm{C}$ the arrows show foam cells (lipoprotein-accumulating macrophages) and arrowheads indicate inflammatory cells in tunica media, both found in only one animal of the treated group. Hematoxylin and eosin stain. Scale Barr: $20 \mu \mathrm{m}$.
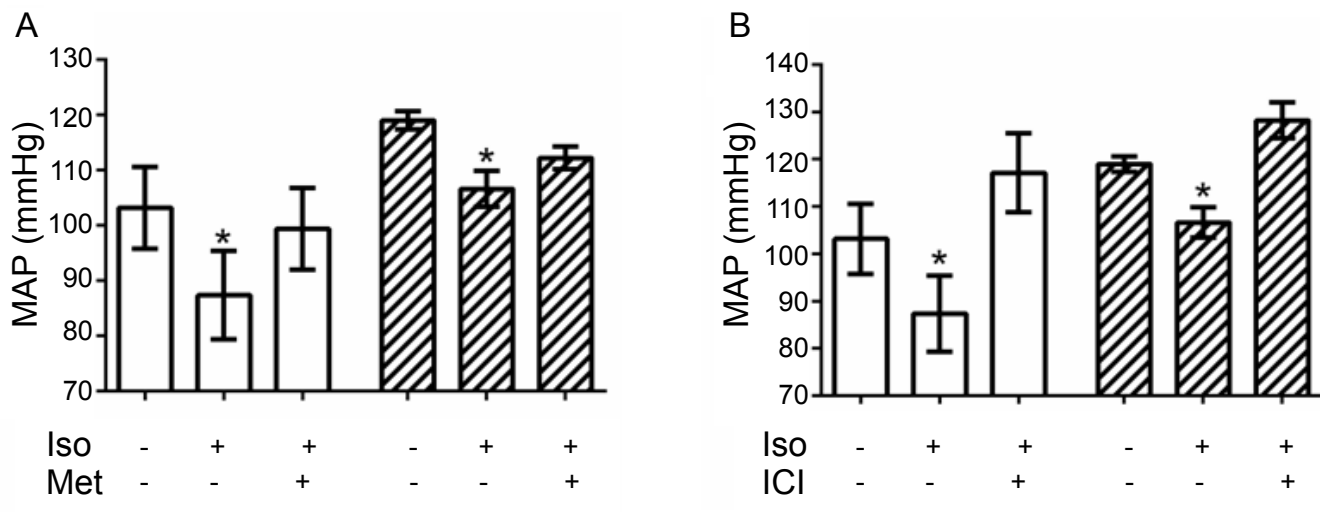

Figure 2: Baseline mean arterial pressure (MAP) and response to $3 \mu \mathrm{g} / \mathrm{kg}$ of isoproterenol infusion before (Iso 1$)$ and after (2.5 mg/kg) metoprolol (panel A) or (1 mg/ $\mathrm{kg}$ ) ICl 118.551 (panel B) (Iso 2) in mice fed a standard diet (CTL; $\mathrm{n=10}$ ) and mice fed with cholesterol-enriched diet for 15 days (CHO; $\mathrm{n}=10$ ). " $p<0.05 \mathrm{compared}$ to baseline in the same group; One-way ANOVA followed by Bonferroni test.

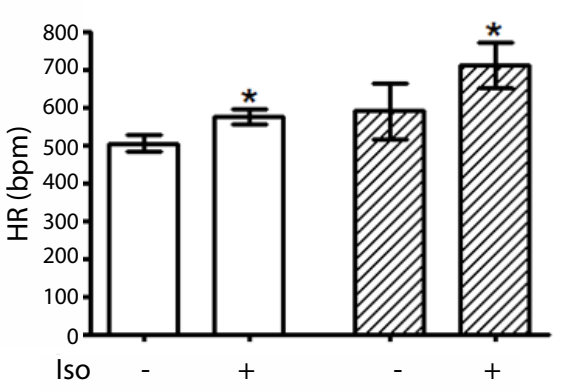

$\square \mathrm{CTL}$

A

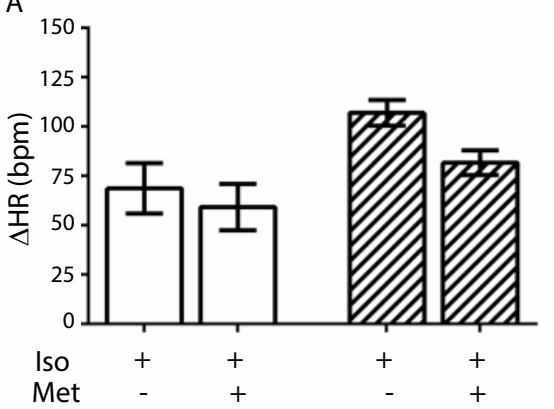

m $\mathrm{CHO}$

\section{$\square$ CTL} m $\mathrm{CHO}$ 


\section{$\square \mathrm{CTL}$ \\ ש $\mathrm{CHO}$}

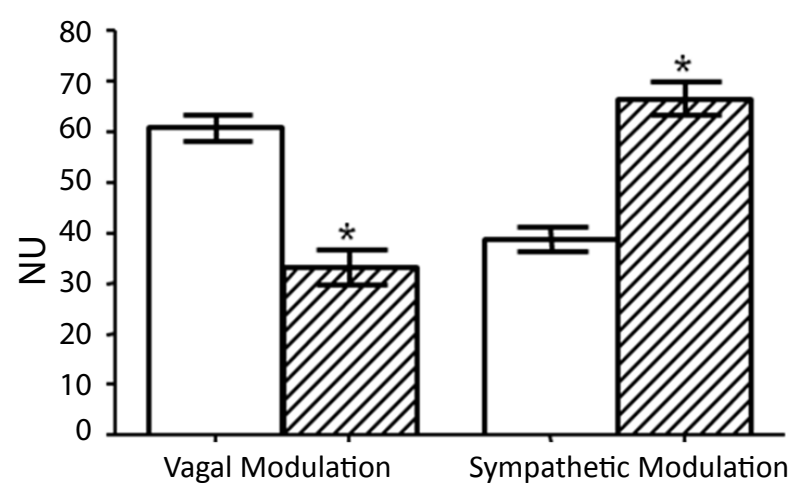

Figure 4: Vagal (HF) and sympathetic (LF) modulation on the heart rate of mice fed standard chow (CTL; $n=10)$ and mice fed cholesterol-enriched diet for 15 days $(\mathrm{CHO} ; \mathrm{n}=9)$. ${ }^{*} p<0.05$ compared to control group (Student $t$ test unpaired). NU-Normalized Units.

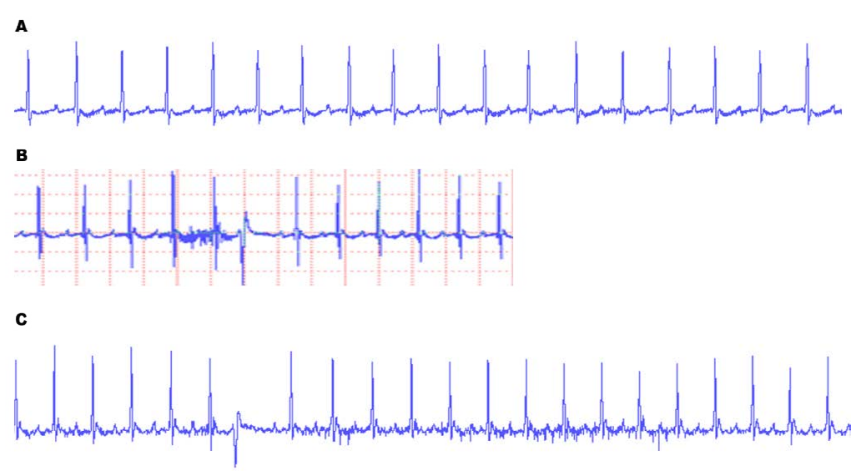

Figure 5: Electrocardiograms of mice fed standart chow (CTL) showing regular basal rhythm (A), ventricular extrasystole after isoproterenol infusion (B) and ventricular extrasystole after $\mathrm{ICl} 118,551$ infusion (C).

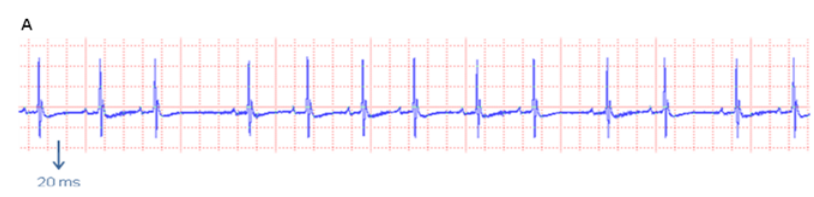

B

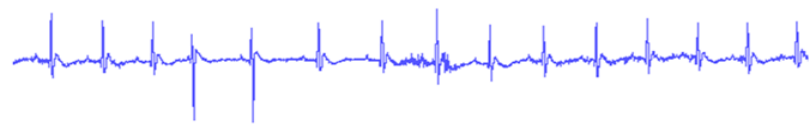

c

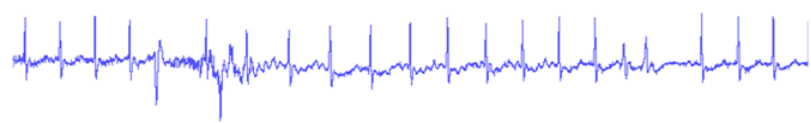

Figure 6: Electrocardiograms of mice fed a high cholesterol diet $(\mathrm{CHO})$ showing irregular rhythm $(A)$, ventricular extrasystoles $(B)$ and ventricular extrasystoles followed by bigeminy (C). type mice fed a cholesterol-enriched diet, indicating a predominance of sympathetic drive over the vagal tonus to the heart, as opposite of what was seen in the control mice. Both, vagal drive reduction as well as sympathetic activity increase is associated with higher incidence of ischemic cardiac events, chronic degenerative diseases, lethal arrhythmias, and sudden death [20-22]. A similar effect of this diet in the autonomic balance has been reported in mice knockout for the LDL receptor [23], in non-obese diabetic mice [16], as well as in a model of familial hypertrophic cardiomyopathy characterized by contractile dysfunction [24]. Indeed, data presented here have shown that mice fed a cholesterol-enriched diet exhibited rhythm disturbances, even in the absence of stimulation, whereas none of the control mice showed such rhythm irregularities.

In the rodents' heart, as in human's, the effect of catecholamines is mediated by $\beta_{1}$ and $\beta_{2}$ adrenergic receptors with a predominance of the $\beta_{1}$ adrenoceptor subtype [25]. $\beta_{2}$ adrenergic receptors are also expressed in the blood vessels, where they mediate vasodilation. Isoproterenol is a full, non-selective $\beta$ adrenoceptor agonist that interacts with both $\beta_{1}$ and $\beta_{2}$-adrenoceptors subtypes [26]. Administration of isoproterenol resulted in significant positive chronotropic and hypotensive responses in mice of both groups. Similar responses were also reported by Rohrer et al. [27]. So, the hypotensive response is probably due to the action of isoproterenol on the $\beta_{2}$-ARs in the vascular smooth muscle and the chronotropic effect is probably due to the interaction of isoproterenol with $\beta_{1}$ - and $\beta_{2}$-ARs in the heart. Additionally, hypotension might have activated the baroreflex that contributed to the heart rate increase. The effect of isoproterenol was more intense in mice fed a cholesterolenriched diet than in mice fed a regular chow.

Neither metoprolol ( $\beta_{1}$-AR selective antagonist) nor ICI 118,551 ( $\beta_{2}$-AR selective antagonist) caused any significant change in MAP and $\mathrm{HR}$ in control or $\mathrm{CHO}$ mice. However, both antagonists canceled the response to isoproterenol. Propranolol, a nonselective $\beta$-AR antagonist [28], significantly increased the MAP of mice in both groups. This response was probably caused by the increase in volume due to the experimental protocol. Furthermore, propranolol significantly reduced the heart rate of the $\mathrm{CHO}$ but had no effect in the control group, what reinforce the hypothesis that $\mathrm{CHO}$ mice have higher sympathetic activity and consequently higher heart rate than control mice.

Mice fed a cholesterol-enriched diet showed greater responsiveness to isoproterenol. Furthermore, the response to isoproterenol was reduced by ICI 118,551 but not by metoprolol. These results suggest that $\beta_{2}$-adrenoceptors play an important role in the cardiac response to isoproterenol in hypercholesterolemic mice.

Chronic exposure of the heart to high concentrations of catecholamines may lead to pathogenic changes in the heart, resulting in progressive deterioration in cardiac function [29]. Sixty percent of the mice fed a diet rich in cholesterol exhibited some change in heart rate probably due to a higher sympathetic drive, while control mice showed no such disorder.

The administration of isoproterenol caused twice arrhythmic events in CHO group than in the CTL group (60\%/30\%, respectively). Partterson et al. reported increased cardiotoxicity, higher risk of cardiac apoptosis in mice knocked out for the $\beta_{2}-\mathrm{AR}$, after chronic stimulation using isoproterenol, as compared to non-genetically manipulated mice. The higher mortality of those mice is probably due to those structural damages leading to lethal arrhythmias [30]. Another study showed that the use of a selective $\beta_{2}$-adrenergic agonist exerted beneficial effect by reducing the size of the infarcted area and increasing cardiac ejection fraction in rats with ischemic cardiomyopathy [31]. 
Citation: Ternes SC, Souza LED, Cruz PL, Mostarda CT, Irigoyen MCC, et al. (2016) $\beta_{2}$-Adrenoceptors Antiarrhythmic Effects in Wild Type Mice Fed a Cholesterol-Enriched Diet. Cardiovasc Pharm Open Access 5: 196. doi: 10.4172/2329-6607.1000196

Page 6 of 6

The stimulation with isoproterenol after $\beta_{1}$-ARs blockade by metoprolol or double blockade by propranolol did not cause any rhythm abnormality in mice of the control group, and cancelled arrhythmias in $\mathrm{CHO}$ mice. However, stimulation with isoproterenol preceded by $\beta_{2}$-AR blockade with ICI118, 551 caused arrhythmias in $60 \%$ of CTL group and $80 \%$ in CHO group. These data, therefore, suggest that $\beta_{2}$-AR exert a protective role against arrhythmias triggered by excessive stimulation of $\beta$-adrenergic receptors. We have reported that in vitro blockade of $\beta_{2}$-AR caused arrhythmia in right atria of LDLr-/-mice and that this effect is more pronounced in atria of mice fed a high cholesterol diet [15].

Hence, data presented in this study demonstrated that intake of high cholesterol diet causes hemodynamic changes and heart rhythm disturbance. Those effects are exacerbated by the blockade of $\beta_{2}$-AR. Data also reinforced the specificity of the role played by each adrenoceptor subtype in the modulation of the cardiac rhythm, highlighting a possible antiarrhythmic protective role played by $\beta_{2}-\mathrm{AR}$ subtype.

\section{References}

1. Smith GD, Shipley MJ, Marmot MG, Rose G (1992) Plasma cholesterol concentration and mortality. The Whitehall Study. JAMA 267: 70-76.

2. Poirier P, Giles TD, Bray GA, Hong Y, Stern JS, et al. (2006) Obesity and cardiovascular disease: pathophysiology, evaluation and effect of weight loss. Arterioscler Thromb Vasc Biol 26: 968-976.

3. Marte AP, Santos RD (2007) Dislipidemia and hypertension: Physiopathology Rev Bras Hipertens 14: 252-257.

4. Daugherty A, Lu H, Rateri DL, Cassis LA (2008) Augmentation of the reninangiotensin system by hypercholesterolemia promotes vascular disease. Future Lipidol 3: 625-636.

5. Campos C, Bertagnolli M, Evangelho J, Tusset C, Belló-Klein A, et al. (2008) Baroreflex sensitivity and oxidative stress in the LDL receptor knockout mice. Exp Toxicol Pathol 60: 329-335.

6. Steinberg SF (1999) The molecular basis for distinct beta-adrenergic receptor subtype actions in cardiomyocytes. Circ Res 85: 1101-1111.

7. Kohout TA, Lefkowitz RJ (2003) Regulation of G protein-coupled receptor kinases and arrestins during receptor desensitization. Mol Pharmacol 63: 9-18.

8. Gordan R, Gwathmey JK, Xie LH (2015) Autonomic and endocrine control of cardiovascular function. World J Cardiol 7: 204-214.

9. Port JD, Bristow MR (2001) Altered beta-adrenergic receptor gene regulation and signaling in chronic heart failure. J Mol Cell Cardiol 33: 887-905.

10. Communal C, Colucci WS (2005) The control of cardiomyocyte apoptosis via the beta-adrenergic signaling pathways. Arch Mal Coeur Vaiss 98: 236-241.

11. Bohm M, Kirchmayr R, Erdmann E (1995) Myocardial Gi alpha protein levels in patients with hypertensive cardiac hypertrophy, ischemic heart disease and cardiogenic shock. Cardiovasc Res 30: 611-618.

12. Ho D, Yan L, Iwatsubo K, Vatner DE, Vatner SF (2010) Modulation of $\beta$-adrenergic receptor signaling in heart failure and longevity: targeting adenylyl cyclase type 5. Heart Fail Rev 15: 495-512.

13. Zhang X, Szeto C, Gao E, Tang M, Jin J, et al. (2013) Cardiotoxic and cardioprotective features of chronic $\beta$-adrenergic signaling. Circ Res 112: 498-509.

14. Zhang W, Yano N, Deng M, Mao Q, Shaw SK, et al. (2011) $\beta$-Adrenergic receptor-PI3K signaling crosstalk in mouse heart: Elucidation of immediate downstream signaling cascades. PLoS One 6: e26581.
15. Wanschel AC, Caceres VM, Moretti Al, Bruni-Cardoso A, de Carvalho HF, et al. (2014) Cardioprotective mechanism of S-nitroso-N-acetylcysteine via S-nitrosated betadrenoceptor-2 in the LDL-/- mice. Nitric Oxide 36: 58-66.

16. Moraes OA, Colucci JA, Souza LE, Scapini KB, Moraes-Silva IC, et al. (2013) Cardiovascular autonomic dysfunction in non-obese diabetic mice. Auton Neurosc: Basic Clin 177: 143-147.

17. Girod WG, Jones SP, Sieber N, Aw TY, Lefer DJ (1999) Effects of hypercholesterolemia on myocardial ischemia-reperfusion injury in LDL receptor-deficient mice. Arterioscler Thromb Vasc Biol 19: 2776-2781.

18. Ma Y, Wang W, Zhang J, Lu Y, Wu W, et al. (2012) Hyperlipidemia and atherosclerotic lesion development in LDLr-deficient mice on a long-term highfat diet. PLoS One 7: e35835.

19. Santana AB, de Souza Oliveira TC, Bianconi BL, Barauna VG, Santos EW, et al. (2014) Effect of high-fat diet upon inflammatory markers and aortic stiffening in mice. Biomed Res Intl 2014: 1-12.

20. Singh JP, Larson MG, Tsuji H, Evans JC, O’Donnell CJ, et al. (1998) Reduced heart rate variability and new-onset hypertension: insights into pathogenesis of hypertension: the Framingham Heart Study. Hypertension 38: 293-297.

21. Billman, GE (2009) Cardiac autonomic neural remodeling and susceptibility to sudden cardiac death: effect of endurance exercise training. Am J Physiol: Heart Circ Physiol 297: H1171-H1193.

22. Metelka R (2014) Heart Rate Variability-Current diagnosis of the cardiac autonomic neuropathy. A review. Biomed Pap Med Fac Unv Palacky Olomouc Czech Repub 158: 327-338.

23. Evangelho JS, Casali KR, Campos C, De Angelis K, Veiga AB, et al. (2011) Hypercholesterolemia magnitude increases sympathetic modulation and coagulation in LDLr knockout mice. Auton Neurosci 20: 98-103.

24. Hardt SE, Sadoshima J (2002) Glycogen synthase kinase-3beta: A nove regulator of cardiac hypertrophy and development. Circ Res 90: 1055-1063.

25. Bernstein D, Fajardo G, Zhao M, Urashima T, Powers J, et al. (2005) Differential cardioprotective-cardiotoxic effects mediated by $\beta$-adrenergic receptor subtypes. Am J Physiol 289: H2441-H2449.

26. Neumann J, Boknik P, Depaoli-Rozch AA, Campo LJ, Rockman HA, et al (1998) Target overexpression of phospholamban to mouse atrium depresses $\mathrm{Ca}^{2+}$ transport and contractility. J Mol Cell Cardiol 30: 1991-2002.

27. Rohrer DK, Chruscinski A, Schauble EH, Bernstein D, Kobilka BK (1999) Cardiovascular and Metabolic alterations in mice lacking both beta1 and beta2 adrenergic receptors. J Biol Chem 274: 16701-16708.

28. Bristow MR (2000) $\beta$-Adrenergic receptor blockade in chronic heart failure Circulation 101: 558-569.

29. Brum PC, Kosek J, Patterson A, Bernstein D, Kobilka B (2002) Abnormal cardiac function associated with sympathetic nervous system hyperactivity in mice. Am J Physiol: Heart Circ Physiol 283: H1838-H1845.

30. Patterson AJ, Zhu W, Chow A, Agrawal R, Kosek J, et al. (2004) Protecting the myocardium: A role for the beta2 adrenergic receptor in the heart. Crit Care Med 32: 1041-1048.

31. Ahmet I, Krawczyk M, Moon C, Lakkatta EG, Talan MI (2004) Beneficial effects of chronic pharmacological manipulation of $\beta$-adrenoceptor subtype signaling in rodent dilated ischemic cardiomyopathy. Circulation 110: 1083-1090. 